\title{
Staff Augmentation during Disaster Response
}

\author{
Romeo Fairley; $₫$ Tatiana Emanuel; Bradley Goettl
}

\author{
University of Texas Health Science Center-San \\ Antonio, San Antonio, Texas, USA \\ Correspondence: \\ Romeo Fairley, MD, MPH, FACEP \\ UT Health School of Medicine \\ Dept. of Emergency Medicine \\ 7703 Floyd Curl Drive, MC 7736 \\ San Antonio, Texas 78229, USA \\ E-mail: FairleyR@uthscsa.edu
}

Conflicts of interest: The authors declare none.

Keywords: ethics; medicolegal; surge staffing

Abbreviations:

APP: advanced practice provider

COVID-19: coronavirus disease 2019

ICU: intensive care unit

MOA: memoranda of agreement

TxEMTF: Texas Emergency Medical Task Force

Received: September 28, 2021

Accepted: October 27, 2021

doi:10.1017/S1049023X22000024

(C) The Author(s), 2022. Published by

Cambridge University Press on behalf of the

World Association for Disaster and Emergency

Medicine.

\begin{abstract}
This article outlines a disaster medicine team response to the Texas-Mexico border during a coronavirus disease 2019 (COVID-19) surge. The team consisted of emergency medicine attending providers, as well as a nurse practitioner and a physician assistant, who were asked to work in the intensive care unit (ICU) under the guidance of an intensivist. The article highlights the medicolegal and ethical implications of providers working outside of their designated scope of practice. A framework for future staff augmentation during a disaster is explained.
\end{abstract}

Fairley R, Emanuel T, Goettl B. Staff augmentation during disaster response. Prehosp Disaster Med. 2022;37(1):1-3.

\section{Background}

A novel coronavirus disease dominated 2020 (coronavirus disease 2019 [COVID-19]), quickly evolving into a pandemic with multiple hot spots across the United States and heavily impacting Texans. During the first surge of COVID-19, the Southwest Texas Regional Advisory Council (STRAC; San Antonio, Texas USA) and Texas Emergency Medical Task Forces (TxEMTFs) received an urgent request for assistance from a regional hospital along the Texas-Mexico border. This regional hospital was experiencing a rapid influx of patients with respiratory complaints and quickly became overwhelmed. During this surge, all hospitals in the region were experiencing similar capacity issues, limiting the number of patients that could be transferred to other facilities. The inability to move or discharge patients led to complete hospital saturation, further limiting resources and stressing the local health system.

This article gives a real-world example of how to augment medical staff during disaster medical response and sets a precedent for providers to potentially deploy outside of their standard scope of practice. The medicolegal and ethical repercussions are discussed.

\section{Mission Description}

The TxEMTF, as part of the Texas Disaster Medical System, is activated on behalf of Texas through a request from the impacted jurisdiction to the Texas Division of Emergency Management. This results in a State Mission Assignment (SMA), coordinated by the appropriate regional advisory council. The purpose of the TxEMTF is to provide a scalable series of medical components to assist communities during disasters. The system is based on a series of memoranda of agreements (MOAs) that allow staff to work during state-declared missions for the TxEMTF system while utilizing their home agencies' credentials, insurance, and payment system. The staff are paid by their home agency; the agencies are reimbursed by the State. This system has been used for years without complication.

In response to the emergent situation, a team of two physicians, two advanced practice providers (APPs), a nurse, and a paramedic were sent to a hospital in need. The physicians were board certified emergency physicians, and the APPs and nurse were regularly employed by an emergency department.

Usually, the TxEMTF staff work under austere conditions in tents, parking lots, or shelters of opportunity. During this mission, there were two important caveats. First, the staff was to work inside of another hospital. The team was given emergency credentialing by the hospital, but insurance coverage and payment was still to be through their home institution. Second, the emergency medicine physicians and acute care APPs were requested to work in the intensive care unit (ICU), covering for an ICU physician who was unable to be in the hospital. The ICU physician was reachable by phone and would electronically evaluate the patients, but the in-person care, daily rounding, and procedures were to be performed by the TxEMTF team. Not having ICU credentials (or specific training), the team was hesitant. We were reassured that the ICU physician would be reachable, this was a desperate 


\begin{tabular}{|l|c|}
\hline \multicolumn{2}{|l|}{ Federal } \\
\hline $\begin{array}{l}\text { Emergency Management Assistance } \\
\text { Compact }\end{array}$ & 1996 \\
\hline Volunteer Protection Act & 2005 \\
\hline $\begin{array}{l}\text { Public Readiness and Emergency } \\
\text { Preparedness (PREP) Act }\end{array}$ \\
\hline State & $\begin{array}{l}\text { Ratified by All 50 States, District of Columbia, } \\
\text { US Virgin Islands, Puerto Rico, Guam, and }\end{array}$ \\
\hline $\begin{array}{l}\text { Emergency } \\
\text { Management } \\
\text { Assistance Compact }\end{array}$ & Northern Mariana \\
\hline Good Samaritan Law & Enacted in all 50 States \\
\hline \multicolumn{2}{|l|}{ Texas Civil Practice \& Remedies Code Chapter 79 } \\
\hline Texas Government Code Sections 418.006, 421.061, and 431.085 \\
\hline Texas Health \& Safety Code Section 81.007 \\
\hline \multicolumn{2}{|c|}{ Fexas Civil Practice \& Remedies Code Chapter 74 } \\
\hline Texas Charitable Immunity and Liability Act of 1987 \\
\hline Texas Senate Bill 752 of 2019 \\
\hline
\end{tabular}

Table 1. Legal Liability Protection

situation, and there was a Navy-based ICU team coming in a few days to replace us. Essentially, there were no other viable options. As we deliberated moving forward with the mission, we considered the medicolegal, personnel and patient safety, as well ethical repercussions.

\section{Medicolegal Concerns}

Liability is often cited as a major concern for medical providers to volunteer or work in disaster response. Disasters are frequently inundated with limited resources, severe stress, and difficult decisions in austere environments creating a situation primed for bad outcomes. In the history of disaster response, there have been zero cases of successful liability lawsuits. Despite this, the repeatedly vocalized concern is that bad outcomes and "sub-standard care" will lead to lawsuits. The idea of standard of care in disaster response has been a topic of debate, with the general consensus being that the standard of care is specifically defined by the situation, and therefore in disasters, it is not anticipated to be and should not be "sub-standard." Therefore, the standard of care is upheld and does not imply a risk of liability lawsuit. For our disaster response, included in the MOA is insurance coverage. During the deployment, our home institution continues to cover medical malpractice insurance (and workers' compensation insurance) regardless of the physical location of a deployment, so long as we are acting within the scope of the mission. In addition, there have been multiple federal and state laws, statues, and codes put in place to protect disaster responders (Table 1). Examples of Texas-specific legal liability protection are listed, however many states share similar legal constructs. None of this implies that disaster responders are not potentially legally responsible to their patients, and criminal lawsuits are possible; however, it would be almost impossible for a disaster responder to have a liability lawsuit against them go to trial.

The largest concern was scope of practice. We were all emergency medicine providers, being asked to work in the ICU, not just as a proceduralist, but daily rounding providers. While the intensivist would be electronically evaluating the patients and regularly communicating with us, without a physical connection, there was room for errors. In addition, while medical trainees rotate on other services, there is no precedent for attending-level physicians from one medical specialty to work under the guidance of a physician in another specialty.

In Texas, the authority for credentialing and limited licensing is delegated to the Texas Medical Board (Austin, Texas USA). Per Rule § 172.20(a): "In the event of an occurrence for which the Governor of the State of Texas has declared a state of emergency, in accordance with the Texas Government Code, the Office of the Governor may temporarily suspend all necessary statutes and rules to allow health care providers to practice medicine, or within the scope of their appropriate licensure, permit, or certification in Texas to assist with disaster response operations." Licensure wasn't an issue; however, all legal documentation and credentialing processes are qualified by that of "scope of practice."

The hospital was more than willing to grant the team the required credentialing, fully knowing our backgrounds. We were still somewhat hesitant to be potentially practicing outside of our scope of practice. We decided that to protect ourselves, we would act as a "consultant." The primary responsibility of the patient would fall on the intensivist provider. We would see the patients, do required procedures within our scope, and document daily notes, including our recommendations as consultant for the care of the patient.

\section{Ethical Considerations}

We had our home institution, the hospital, and the government all stating we were taking on a necessary and legal duty; but ethically, were we right? Attention to the seven mid-level ethical principles of medicine has been developed as a construct for answering difficult questions in medicine (Table 2). ${ }^{2}$ Below is a brief outline of these principles and how they apply to this situation.

Non-maleficence is embodied by the Hippocratic statement of "primum nil nocere" (first of all, do no harm). It could be argued in this situation, by placing non-intensivist staff in an ICU setting, the risk of harm was real. Unfortunately, the alternative seemed far worse. If we did not care for these patients, they would be put on a hospitalist service (also non-intensivist trained) that was already well-beyond their safe patient loads.

Beneficence is the obligation to produce benefit and have the welfare of the patient as a goal. The goal of all TxEMTF missions is to aid patients involved in disaster scenarios. As a team, we all agreed that our goal was to help however we could.

Health maximization can be a difficult goal to achieve in medicine as it is generally thought of in terms of societal outcomes. The best thing for an individual may be at odds with society's best interest. This principle is frequently the underlying cause of angst for medical personal making decisions in the resource-constrained environment of a disaster. For us, as a team, we believed our mission to assist in the ICU was the place we could be of maximal value to the local community.

Efficiency can be a difficult principle to fully evaluate. There are almost endless repercussions to any decision, and therefore understanding the full cost/benefit analysis can be unobtainable. During our mission, the emergency department was full of admitted patients but had only a slow volume of new patients that the on-duty emergency medicine team was able to care for. We believed in order to maximize our impact, and therefore the efficiency of cost/benefit, we would be best utilized in other areas of the hospital.

Respect for autonomy identifies that each person has a right to choose their medical care so long as they have capacity. 


\begin{tabular}{|l|}
\hline Non-Maleficence \\
\hline Beneficence \\
\hline Health Maximization \\
\hline Efficiency \\
\hline Respect for Autonomy \\
\hline Justice \\
\hline Proportionality \\
\hline
\end{tabular}

Table 2. Ethical Principles

Unfortunately, the bulk of the patients the team would interact with lacked capacity due to their acute medical illness. Many were intubated, hypoxic, and extraordinarily ill. By proxy, the elected local health authority could assist in the patients' decision regarding us assisting them. The local health authority was closely involved in authorizing and supporting our mission.

The ethical principle of justice refers to all people having a right to equal opportunities and a fair distribution of health outcomes. This is another principle that can help guide limited resource distribution. During our mission, we cared for the entire hospital by responding as the rapid response team. We believe our mission was equitable.

The final ethical principle of proportionality is both a normative ethical principle and a methodological principle. By principle, a decision's benefits must outweigh its negative consequences. Methodologically, the idea of proportionality allows us to weigh our decisions based on the other ethical principles. For example, our mission cost the State of Texas money, our home institutions had to back-fill our shifts, we were not specifically trained in intensive care, and yet we strongly believed our mission was doing good for the community and qualified as a justified ethical mission.

\section{Conclusion}

Our mission met the criteria of a legally sound and protected, ethically justified endeavor. As we endured the overwhelming circumstances of the communities' situation, we continually reminded ourselves as a team, we were there doing good for the community. For days, we rounded on ICU patients and managed their daily needs. Rapidly, knowledge of our presence and abilities became known to the other hospital providers. We became the code response team, the intubation team, the central line team, the "whatever was needed" team for the entire hospital. It was a grueling six days surrounded by incredibly ill patients in a stressed hospital, caring for patients alongside amazing, dedicated staff and providers. No significant complications occurred; the team went home and the mission was considered a success.

This experience highlights the broad scope capable of emergency medicine providers; however, many physicians are crosstrained and capable of supplementing staff during a crisis. For example, anesthesia, surgery, and internal medicine providers are all trained in critical care medicine and could assist in an ICU setting during a disaster. Family medicine and all internal medicine fellowship trained physicians are trained in hospitalist medicine. In addition, APPs may be a significant benefit to augmenting staff shortages. Advanced practice registered nurses are required to practice within the role and the population focus area in which they have been formally educated and licensed by the Texas Board of Nursing (Austin, Texas USA). Currently, an emergency declaration does not allow for nurse practitioners to exceed their scope of practice, even with direct physician oversight. These rules may require adjusting for disaster response. Physician assistants are not constrained by scope of practice in their credentialing or licensing. This article sets a precedent for medical providers to work outside of their standard scope of practice while being supervised by an attending physician.

\section{Acknowledgements}

The authors would like to thank CJ Winckler, Keaton Mattick, David Wampler, Joe Palfini, and Eric Epley for their support, leadership, and guidance.

\section{References}

1. Schultz CH, Annas GJ. Altering the standard of care in disasters-unnecessary and dangerous. Ann Emerg Med. 2012;59(3):191-195.
2. Schröder-Bäck P, Duncan P, Sherlaw W, Brall C, Czabanowska K. Teaching seven principles for public health ethics: towards a curriculum for a short course on ethics in public health programs. BMC Med Ethics. 2014;15:73. 